be increased in blood sucking insects, such as tsetse flies, if the females were fed on pregnant hosts.

In 1964, nearly 350 fertilized females of Glossina austeni were fed on pregnant goats and a similar number on non-pregnant goats. The females fed on pregnant goats lived significantly longer and produced significantly more and heavier pupae than the controls ${ }^{4}$. The investigation was started towards the end of a toxic period, believed to have been due to slight insecticidal contamination, and the control values were sub-standard. It was decided to await the following year's goat breeding season and to undertake a second series of experiments, the results of which are discussed below.

When it seemed certain that the seven experimental goats were pregnant, a continuing series of alternating experimental and control cages was set up; each cage held twenty-five, 4 day old, fertilized female $G$. austeni. This continued until parturition. In cages set up towards the end of the 5 month gestation period flies had progressively fewer feeds from pregnant hosts, but as found in the previous year even a small number of feeds on pregnant hosts sufficed to establish the superiority of the experimental flies over the controls.

In all, nearly 1,050 females were fed on pregnant goats and a similar number on non-pregnant individuals. By the end of the fifth reproductive cycle, when the flies were 8 weeks old, 61 per cent of the experimental flies were still alive compared with 39 per cent of the controls; the difference is significant $\left(\chi^{2}=101 \cdot 1 ; P<0 \cdot 001\right)$. The 1,048 experimental flies had produced 2,865 pupae, the 1,044 control flies had produced only 1,852 pupae, and the mean weight of the former was $1 \mathrm{mg}$ greater. The larger pupal yield from the experimental flies was a result of both better survival and an improved rate of reproduction. By dividing the crude data into sub-experiments of 200-250 experimental flies and plotting their pupal yields against the host gestation period, a trend has been revealed which suggests that the effect of the beneficial factor on pupal yield increases to become maximal in the ninth to fourteenth week of pregnancy and then operates at a lower level.

By the end of the fourteenth reproductive cycle when the flies were 20 weeks old, 398 experimental females had produced 1,963 pupae with 11 per cent of the females surviving, whereas 399 control females had produced only 920 pupa $\theta$ with 3 per cent of the females surviving. The period during which these flies were fed on pregnant goats, before parturition necessitated their transfer to nonpregnant goats, ranged from 134 days for the first cage to be set up to 71 days for the last.

Clearly, feeding $G$. austeni on pregnant hosts greatly increases their reproductive ability. Should the gestation period of their wild hosts coincide with the early rains, the great increase in tsetse populations which may oceur at this season could be in part due to host pregnancy, and not entirely to the amelioration of climatic conditions. It is important to know whether in nature female tsetse are attracted in greater numbers to, say, pregnant oxen than to non-pregnant or male individuals, possibly by a difference in scent. If this is so, the results described above could be attributed to the more avid feeding of female tsetse on pregnant animals, and not necessarily to some factor in the blood of the pregnant hosts.

T. A. M. NASH

A. M. JORDAN

J. A. BOYLE

Tsetse Research Laboratory,

University of Bristol,

School of Veterinary Science,

Langford, near Bristol.

${ }^{2}$ Mead-Briggs, A. R., and Rudge, A. J. B., Nature, 187, 1136 (1960).

${ }^{2}$ Mead-Briggs, A. R., J. Exp. Biol., 41, 371 (1964).

${ }^{3}$ Rothschild, M., Endeavour, 24, No. 93, 162 (1965).

- Nash, T. A. M., Kernaghan, R. J., and Boyle, J. A., Ann. Trop. Med. Parasit., 60, $39(1966)$

\section{Photoperiodic Stimulation of Egg Laying in the Land Snail Helix aspersa}

WE report here early results of an investigation of the relation between photoperiod and various aspects of the physiology and reproduction of the land snail, Helix aspersa. It was suggested recently that maturation of gametes may be initiated by annual temperature fluctuations and is perhaps correlated with changes in illumination. There does not seem to be much information on the influence of light. Induction of egg laying in the pulmonate pond snail Lymnaea palustris given light periods of $13 \cdot 5 \mathrm{~h}$ or more has been reported and interruption of the dark period on a short day schedule is also effective?

Our observations were made on mature $H$. aspersu collected from their natural habitat in a well watered garden in California. In this habitat, active individuals are observed throughout the year. Copulation and egg laying reach a peak in late June and early July. Observations of laboratory maintenance, growth, and reproductive behaviour of these animals have recently been reported ${ }^{3,4}$.

On July 15 and again on September 15, 1965, forty animals were brought into the laboratory and divided into four groups of ten. In two of the groups the distal half of the optic tentacles was removed with fine scissors. The remaining two groups were sham operated in an adjacent region of the foot. Each group of animals was placed in a vented clear plastic container with moist garden soil and grass clippings, and placed in one of two incubators at a temperature of $17^{\circ} \mathrm{C}$. Automatically controlled fuorescent lighting provided a regime of $15 \mathrm{~h}$ of light and $9 \mathrm{~h}$ of dark in one incubator and $9 \mathrm{~h}$ of light and $15 \mathrm{~h}$ of dark in the other. A group of animals without tentacles and a group of sham operated animals were placed in each incubator on the dates mentioned. Light intensity was 60-80 ft.-candles at the surface of the clear container. The snails were kept supplied with fresh lettuce.

Table 1. NUMBer OF EGg Clusters

\begin{tabular}{|c|c|c|c|c|}
\hline \multirow[b]{2}{*}{$\begin{array}{l}\text { Date of } \\
\text { collection }\end{array}$} & \multicolumn{2}{|c|}{$15 \mathrm{~h}$ light and $9 \mathrm{~h}$ dark } & \multirow{2}{*}{$\begin{array}{c}9 \text { h light an } \\
\text { Sham } \\
\text { operaterl }\end{array}$} & \multirow{2}{*}{$\begin{array}{l}15 \mathrm{~h} \text { darh } \\
\text { Tentacle } \\
\text { removed }\end{array}$} \\
\hline & $\begin{array}{l}\text { Sham } \\
\text { operated }\end{array}$ & $\begin{array}{l}\text { Tentacle } \\
\text { removed }\end{array}$ & & \\
\hline $\begin{array}{l}\text { aly } 15,1 \\
\text { eptembe }\end{array}$ & $\begin{array}{l}2 \\
6(1)\end{array}$ & $\begin{array}{l}6 \\
0(2)\end{array}$ & $\begin{array}{l}0 \\
0(1)\end{array}$ & $\begin{array}{l}0 \\
0\end{array}$ \\
\hline
\end{tabular}

Numbers in parentheses indicate the number of animals in each group which have died since the start of the experiment.

Table 1 indicates that egg laying was observed in both detentacled and sham operated snails when they were maintained on a schedule of $15 \mathrm{~h}$ of light each dav. The number of eggs in a eluster ranged from twenty-two to sixty-one.

In this stylommatophoran genus the eye is borne at the tip of the tentacle and clearly the response is not necessarily mediated by the eye. Removal of the optic tentacles in certain pulmonate slugs produces an increase in the number of oocytes in the ovotestis ${ }^{5}$. It should be noted that no egg laying occurred in any group we observed in a $9 \mathrm{~h}$ light regime. Hence, whether or not such an increase? is produced in Helix, removal of the optic tentacles is not: a sufficient stimulus to lay eggs.

Histological and physiological investigation of this. response is in progress.

GWEN J. STEPHENS Grover C. Stephens

Division of Biological Sciences.

University of California,

Irvine, California.

${ }^{1}$ Fretter, V., and Graham, A., in Physiology of Mollusca (edit. by Wilbur, $\mathrm{K}$, and Yonge C. M ) 127 (Academic Press, New York and London 1964).

${ }^{2}$ Jenner, C. E., Anat. Rec.,11, 151 (1951).

s Herzberg, F., and Herzberg, A., Amer. Midl. Natur., 68, 297 (1962).

4 Herzberg, F., Amer. Zool., 5, 254 (1965).

5 Pelluet, D., Canad, J. Zool., 42, 195 (1964). 